\title{
Mitogen-activated protein kinase inhibition enhances the antitumor effects of sporamin in human pancreatic cancer cells
}

\author{
CUI-JUAN QIAN ${ }^{1,2}$, YONG-XIAO QI ${ }^{2}$, SHENG ZHONG $^{2}$, JU-PING ZENG $^{2}$, XIAO-YING CHEN $^{2}$ and JUN YAO ${ }^{2}$ \\ ${ }^{1}$ Department of Gastroenterology, Taizhou Central Hospital, Taizhou University Hospital; \\ ${ }^{2}$ Institute of Tumor, School of Medicine, Taizhou University, Taizhou, Zhejiang 318000, P.R. China
}

Received October 6, 2016; Accepted January 17, 2018

DOI: $10.3892 / \mathrm{ol} .2018 .8746$

\begin{abstract}
Sporamin, a sweet potato tuber storage protein, is a Kunitz-type trypsin inhibitor (TI) that has exhibited antitumor activity through poorly defined mechanisms in a number of types of tumor cells. The present study aimed to analyze the combined effects of sporamin and three mitogen-activated protein kinase (MAPK) inhibitors, PD98059, SP600125 and SB203580, on the pancreatic cancer cell line, PANC-1. Cell proliferation activity was assessed using a ${ }^{3} \mathrm{H}$-thymidine incorporation assay, and cell viability was analyzed using an MTT assay. Apoptosis was assayed by flow cytometry and fluorescence microscopy. Protein expression levels in PANC-1 cells were determined by western blotting. The results of this analysis demonstrated that sporamin induced a temporary increase in the phosphorylation of MAPKs, including phosphorylated extracellular signal regulated-kinase $1 / 2$, phosphorylated c-Jun amino-terminal protein kinase $1 / 2$ and phosphorylated p38-MAPK, in a concentration-dependent manner. However, treatment with MAPK inhibitors promoted the inhibition of cell proliferation and viability, and the induction of apoptosis in sporamin-treated PANC-1 cells. In conclusion, the present study demonstrated that MAPK inhibition enhanced the antitumor activity of sporamin in PANC-1 cells.
\end{abstract}

Correspondence to: Professor Jun Yao, Institute of Tumor, School of Medicine, Taizhou University, 1139 Shifu Road, Jiaojiang, Taizhou, Zhejiang 318000, P.R. China

E-mail: yaojuntzu@yeah.net

Abbreviations: TI, trypsin inhibitor; PC, pancreatic cancer; MAPK, mitogen activated protein kinase; p38, p38-mitogen activated protein kinase; ERK, extracellular signal-regulated protein kinase; JNK, c-Jun amino-terminal protein kinase; DMEM, Dulbecco's modified Eagle's medium

Key words: sporamin, pancreatic cancer, extracellular signal-regulated kinase 1/2, janus kinase, p38-mitogen activated kinase, mitogen activated kinase inhibitors

\section{Introduction}

Pancreatic cancer (PC) is among the most aggressive types of solid tumor, and has the highest rate of cancer-associated mortality worldwide (1). Despite advances in surgical techniques, chemotherapy and radiotherapy, the long-term survival rate for patients with PC has not significantly increased since 1977 (2). Therefore, further research into alternative therapies for PC, which has fewer associated toxicities, is urgently required.

Trypsin inhibitors (TIs) are widely distributed in plants and animals, and certain types of TIs have exhibited antitumor activity in several types of tumor cells (3-5). Although no approved therapies directly targeting trypsin directly are currently available, development of novel and more specific TI therapies is underway (3-5). Sporamin, a sweet potato tuber storage protein, is a Kunitz-type TI that has been demonstrated to induce antitumor effects in vitro and in vivo $(4,5)$. Although the role and mechanism of sporamin as an antitumor agent remain unclear, the previous research has indicated that sporamin can mediate the regulation of specific signaling pathways (5). For example, sporamin was demonstrated to inhibit cell growth and induce apoptosis of human tongue cancer cells by downregulating RAC serine/threonine-protein kinase/glycogen synthase kinase-3 signaling (5). However, to the best of our knowledge, the antitumor effects of sporamin in PC have not been previously investigated.

Mitogen-activated protein kinases (MAPK) are critically involved in the signaling cascades that govern various critical processes, including cell proliferation, differentiation, apoptosis and survival (6). MAPKs are conserved enzymes that connect cell-surface receptors to their regulatory targets within cells (7). The major MAPKs include the extracellular signal-regulated protein kinase (ERK), c-Jun N-terminal protein kinase (JNK) and p38 mitogen activated-protein kinase (p38), which have been identified as sub-families of MAPK (8). MAPKs are constitutively activated in PC (9). Therefore, MAPKs and their associated genes may provide more detailed insights into the mechanism behind the antitumor activity of sporamin in PC cells.

The present study investigated the effects of sporamin on the proliferation, viability and apoptosis of PC cells, and determined the roles of MAPKs in the antitumor activity of sporamin in PC cells. The results of the present study 
demonstrated that the combined treatment of PC cells with sporamin and MAPK inhibitors elicited a superior response to treatment with either sporamin or MAPK inhibitor treatment alone. This result supports the hypothesis that a sporamin and MAPK inhibitor combination treatment may be used as a PC therapy. The present study may provide a novel strategy for the development of targeted antitumor drugs for PC.

\section{Materials and methods}

Cell line and materials. The human PC PANC-1 cell line (American Type Culture Collection, Manassas, VA, USA), was cultured in Dulbecco's Modified Eagle Medium (DMEM) (Gibco; Thermo Fisher Scientific, Inc., Waltham, MA, USA) with $10 \%$ heat-inactivated fetal bovine serum (FBS; Gibco; Thermo Fisher Scientific, Inc.), $100 \mathrm{mg} / 1$ streptomycin and $100 \mathrm{kU} / 1$ benzylpenicillin at $37^{\circ} \mathrm{C}$ in an incubator containing humidified air and $5 \% \mathrm{CO}_{2}$. Sporamin was purified from fresh sweet potato tubers, as previously described (5). The specific phospho-ERK inhibitor PD98059, phospho-JNK specific inhibitor SP600125 and phospho-p38 specific inhibitor SB203580 were purchased from Calbiochem (Merck KGaA, Darmstadt, Germany).

Preparation of cell lysates. For western blot analysis, PANC-1 cells were cultured in 6-well culture plates to $80-90 \%$ confluence, then nutrient-starved for $24 \mathrm{~h}$ in serum-free DMEM. Sporamin was added at 0, 25, 50 and $100 \mu \mathrm{M}$ for $24 \mathrm{~h}$. For MAPK inhibition experiments, the cells were pretreated for $10 \mathrm{~min}$ with $20 \mu \mathrm{M}$ SP600125, $10 \mu \mathrm{M}$ SB203580 or $20 \mu \mathrm{M}$ PD98059 prior to sporamin treatment. Following 3 washes in PBS at $4^{\circ} \mathrm{C}$, the cells were lysed in $60 \mu 1$ lysis buffer $(50 \mathrm{mmol} / \mathrm{NaCl}, 0.5 \mathrm{mmol} / \mathrm{ml}$ phenylmethylsulfonyl fluoride, $2 \mathrm{mmol} / \mathrm{ml} \mathrm{Na}_{3} \mathrm{VO}_{4}$, and $10 \mathrm{mmol} / \mathrm{ml} \mathrm{HEPES}$ at $\mathrm{pH} 7.4$, with $0.01 \%$ Triton $\mathrm{X}-100$ and $10 \mathrm{mg}$ leupeptin) at $4^{\circ} \mathrm{C}$ for $5 \mathrm{~min}$. The cell lysates were obtained by centrifugation at $14,000 \mathrm{x}$ g at $4^{\circ} \mathrm{C}$ for $10 \mathrm{~min}$. The concentrations of proteins were determined using an Enhanced bicinchoninic acid protein assay kit (Beyotime Institute of Biotechnology, Haimen, China).

Western blot analysis. SDS sample buffer $(0.33 \mathrm{~mol} / \mathrm{l}$ Tris- $\mathrm{HCl}, 10 \%$ (w/v) SDS, $40 \%$ (v/v) glycerol, and $0.4 \%$ bromophenol blue), was added to the cell lysates (a buffer:lysate ratio of 1:4). Subsequent to heating for $5 \mathrm{~min}$ at $100^{\circ} \mathrm{C}, 20 \mu \mathrm{g}$ extracted protein was subjected to $10-12 \%$ SDS-PAGE. The protein was transferred into a nitrocellulose membrane, which was then blocked at $25^{\circ} \mathrm{C}$ for $1 \mathrm{~h}$ with $5 \%$ bovine serum albumin (Sigma-Aldrich; Merck KGaA) in $50 \mathrm{mmol} / 1$ Tris-HCl, $150 \mathrm{mmol} / 1 \mathrm{NaCl}$ and $0.1 \%$ Tween-20 ( $\mathrm{pH}$ 7.4). The blots were incubated with primary antibodies against phospho-ERK1/2 (catalog no. 4370), total ERK1/2 (catalog no. 9102), phospho-JNK1/2 (catalog no. 9251), total JNK1/2 (catalog no. 9252), phospho-p38 (catalog no. 9211) and total p38 (catalog no. 9212) (all used at a dilution of 1:1,000, and acquired from Cell Signaling Technology, Inc., Danvers, MA, USA) at $4^{\circ} \mathrm{C}$ overnight. This was followed by a 2-h incubation at room temperature with horseradish peroxidase-conjugated anti-rabbit (catalog no. 7074) or anti-mouse (catalog no. 7076) IgG secondary antibodies (acquired from
Cell Signaling Technology, Inc., Danvers, MA, USA; used at a dilution of 1:2,000). Immunoreactive signals were visualized using Pierce ${ }^{\mathrm{TM}}$ enhanced chemiluminescence western blotting substrate (Merck $\mathrm{KGaA}$ ) and scanned using an LAS-4000 imaging system (Fujifilm Holdings Corporation, Tokyo, Japan).

Determination of cell proliferation activity. PANC-1 cells were seeded in 24-well plates in DMEM supplemented with $10 \%$ FBS and grown to $80 \%$ confluence. The cultures were then rinsed in DMEM and incubated with sporamin $(50 \mu \mathrm{M})$, with or without inhibitor pre-treatment: $20 \mu \mathrm{M}$ PD98059, $20 \mu \mathrm{M}$ SP600125 or $10 \mu \mathrm{M}$ SB203580, and serum-free DMEM for $12 \mathrm{~h}$. Cells were then cultured with $1.35 \times 10^{4} \mathrm{~Bq} / \mathrm{l}^{3} \mathrm{H}$-thymidine for another $12 \mathrm{~h}$. The supernatant was aspirated and washed twice with PBS to remove excess ${ }^{3} \mathrm{H}$-thymidine. The cells were then resuspended in $0.2 \mathrm{~mol} / 1 \mathrm{NaOH} .{ }^{3} \mathrm{H}$-Thymidine incorporation activity was determined with a $\left[{ }^{3} \mathrm{H}\right]$ thymidine incorporation assay (Sigma-Aldrich; Merck KGaA) by scintillation counting (LS6500; Beckman Coulter, Inc., Brea, CA, USA).

Cell viability assay. To assess the effects of sporamin on the viability of PANC-1 cells, an MTT assay was performed. PANC-1 cells were plated in 96-well plates and grown to $80 \%$ confluence. The cultures were then rinsed in DMEM and incubated with sporamin $(50 \mu \mathrm{M})$, with or without inhibitor pre-treatment: $20 \mu \mathrm{M}$ PD98059, $20 \mu \mathrm{M}$ SP600125 or $10 \mu \mathrm{M}$ SB203580 in serum-free DMEM for $24 \mathrm{~h}$. MTT was added at a final concentration of $0.5 \mathrm{~g} / \mathrm{l}$. The cultures were removed from the incubator $1 \mathrm{~h}$ later and the formazan crystals were solubilized in a solution including containing $10 \%$ (v/v) Triton $\mathrm{X}-100$ and $0.1 \mathrm{~mol} / \mathrm{l} \mathrm{HCl}$ in $100 \%$ isopropanol equal to the volume of DMEM $(100 \mu \mathrm{l})$ culture medium. The absorbance was measured at $570 \mathrm{~nm}$ using a microplate reader (Bio-Rad Laboratories, Inc., Hercules, CA, USA).

Flow cytometry analysis for apoptosis. An Annexin V-Fluorescein Isothiocyanate (FITC)/Propidium Iodide (PI) Apoptosis Detection kit (BD Biosciences, San Jose, CA, USA) was used to detect apoptosis according to the manufacturer's protocol. Briefly, the cells were incubated with sporamin (50 $\mu \mathrm{M})$, with or without inhibitor pre-treatment: $20 \mu \mathrm{M}$ PD98059, $20 \mu \mathrm{M}$ SP600125 or $10 \mu \mathrm{M} \mathrm{SB} 203580$ for $24 \mathrm{~h}$. Adherent and non-adherent cells were pooled and harvested by centrifugation at $100 \mathrm{xg}$ for $5 \mathrm{~min}$, washed twice with $4^{\circ} \mathrm{C}$ PBS, and resuspended in $1 \mathrm{X}$ binding buffer $(140 \mathrm{mM} \mathrm{NaOH}$, $10 \mathrm{mM}$ HEPES and $2.5 \mathrm{mM} \mathrm{CaCl}_{2} ; \mathrm{pH} 7.4$ ), at a concentration of $1 \times 10^{6}$ cells $/ \mathrm{ml}$. A total of $1 \times 10^{5}$ cells were transferred to a 5-ml culture tube, and stained with $5 \mu \mathrm{l}$ Annexin V-FITC and $5 \mu \mathrm{l} \mathrm{PI}$ for $15 \mathrm{~min}$ at room temperature in darkness. Finally, $400 \mu 11 \mathrm{X}$ binding buffer was added, and the cells were analyzed using a BD FACSCalibur ${ }^{\mathrm{TM}}$ flow cytometer with BD CellQuest $^{\mathrm{TM}}$ Pro software version 6.0 (BD Biosciences, San Jose, CA, USA).

Morphological determination and quantification of apoptosis. Cells were cultured in 12-well plates at a density of $1 \times 10^{5}$ cells/well, and incubated with sporamin $(50 \mu \mathrm{M})$, with or without inhibitor pre-treatment: $20 \mu \mathrm{M}$ PD98059, $20 \mu \mathrm{M}$ 
SP600125 or $10 \mu \mathrm{M} \mathrm{SB} 203580$ for $24 \mathrm{~h}$. For the nuclear staining assay, cells were fixed with $4 \%$ paraformaldehyde at $4^{\circ} \mathrm{M}$ for $15 \mathrm{~min}$ (pH 7.4) and stained with $0.5 \mu \mathrm{g} / \mathrm{ml}$ DAPI (Sigma-Aldrich, Merck $\mathrm{KGaA}$ ) for $5 \mathrm{~min}$ at room temperature. Images were acquired using a fluorescence microscope (magnification, x200; DMI4000B; Olympus Corporation, Tokyo, Japan). Typical apoptotic nuclear morphologic changes, including condensed and fragmented nuclei, were considered to be indicative of apoptosis, and were easily distinguishable from intact nuclei by microscopy. A total of six randomly chosen fields of view were examined with $<500$ cells scored in each, and the percentage of apoptotic cells was calculated.

Statistical analysis. All data are presented as the mean \pm standard deviation. One-way analysis of variance, followed by Dunnett's post hoc test, was applied to analyze the differences between groups using SPSS 18.0 for Windows (SPSS Inc., Chicago, IL, USA). P $<0.05$ was considered to indicate a statistically significant difference.

\section{Results}

Effect of sporamin on the activation of MAPK in PANC-1 cells. To address the involvement of MAPK in sporamin-induced cell growth suppression and apoptosis directly, phospho-ERK1/2, phospho-JNK1/2 and phospho-p38 protein expression levels were determined by western blotting. As demonstrated in Fig. 1, sporamin treatment at $25-100 \mu \mathrm{M}$ for $24 \mathrm{~h}$ stimulated an increase in phospho-ERK1/2, phospho-JNK1/2 and phospho-p38 protein expression in in a concentration-dependent manner. These results indicated that sporamin increased the activation of MAPK proteins in PANC-1 cells. As $50 \mu \mathrm{M}$ sporamin induced a marked increase in the activation of MAPK proteins, the following experiments involved cell treatment at a sporamin concentration of $50 \mu \mathrm{M}$.

Effect of MAPK inhibitors on sporamin-induced activation of MAPKs in PANC-1 cells. In PANC-1 cells treated with PD98059, SP600125 or SB203580 for 10 min prior to sporamin-treatment, the sporamin-induced phosphorylation of ERK1/2 (Fig. 2A), JNK1/2 (Fig. 2B) and p38 (Fig. 2C) was markedly decreased compared with cells treated with sporamin alone or with untreated cells. These results demonstrated that the MAPK inhibitors prevented the sporamin-induced activation of MAPK proteins in PANC-1 cells.

Effect of MAPK inhibitors on sporamin-induced inhibition of cell proliferation and viability in PANC-1 cells. Whether the MAPK inhibitors could achieve a synergistic suppressive effect on cell growth with sporamin was investigated. $\mathrm{A}{ }^{3} \mathrm{H}$-thymidine incorporation activity assay revealed that there was a significant decrease in the proliferation of PANC-1 cells when they were pre-treated with MAPK inhibitors, compared with PANC-1 cells treated with sporamin or with a MAPK inhibitor alone (Fig. 3A). An MTT assay revealed that cell viability was also significantly reduced in cells pre-treated with MAPK inhibitors, compared with cells treated with sporamin or a MAPK inhibitor alone (Fig. 3B). These results demonstrated that MAPK inhibitors enhanced the sporamin-induced inhibition of cell proliferation activity and viability in PANC-1 cells.

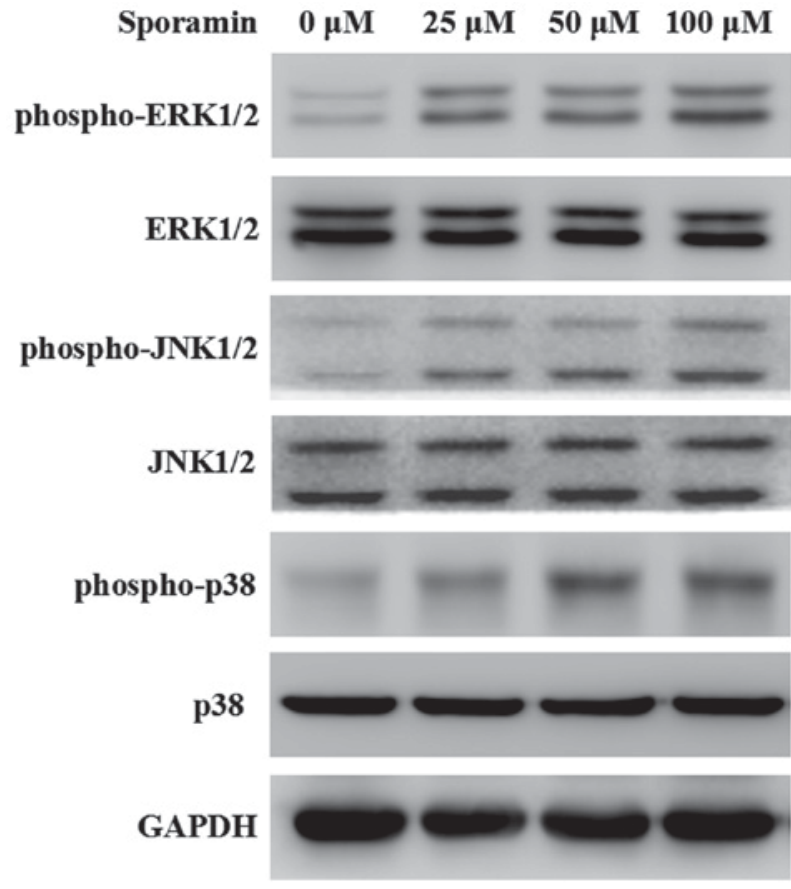

Figure 1. Effect of sporamin on the activation of MAPKs in PANC-1 cells Western blotting revealed the concentration-dependent activation of ERK1/2, JNK1/2 and p38 following a 10-min sporamin treatment in PANC-1 cells MAPK, mitogen-activated protein kinase; ERK, extracellular signal-regulated kinase; JNK, c-Jun N-terminal protein kinase; p38, p38-MAPK.

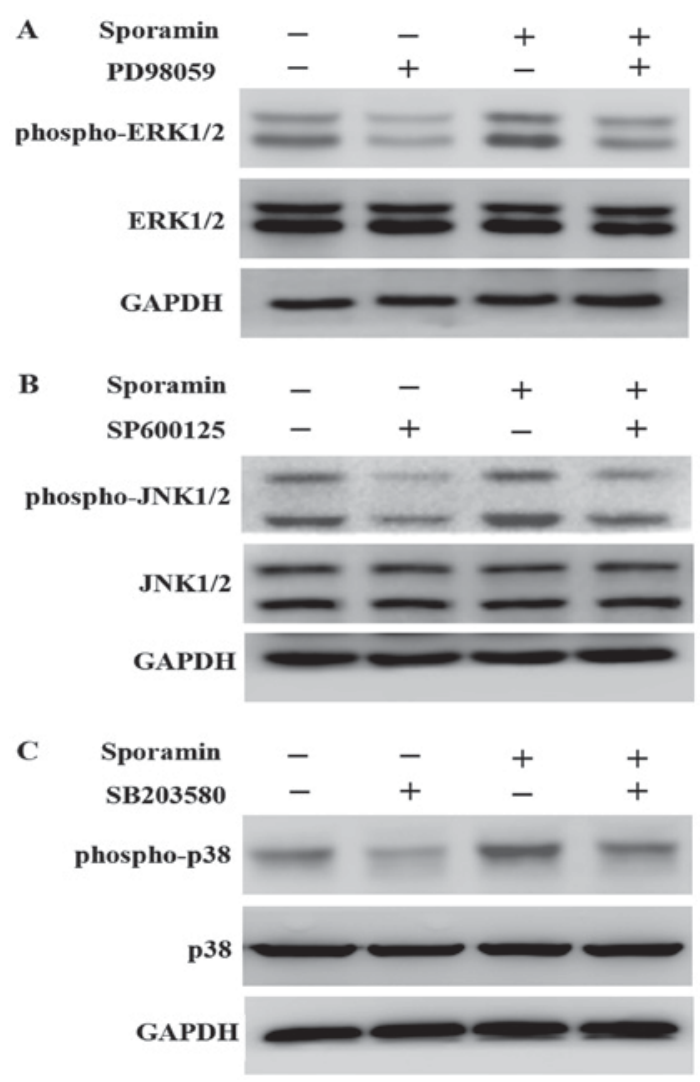

Figure 2. Effect of MAPK inhibitors on the sporamin-induced activation of MAPK proteins in PANC-1 cells. Cells were treated with sporamin $(50 \mu \mathrm{M})$, with or without inhibitor pre-treatment: $20 \mu \mathrm{M}$ PD98059, $20 \mu \mathrm{M}$ SP600125 or $10 \mu \mathrm{M}$ SB203580. (A) ERK1/2 activation, (B) JNK1/2 activation, and (C) p38 activation was analyzed by western blotting. MAPK, mitogen-activated protein kinase; ERK, extracellular signal-regulated kinase; JNK, c-Jun N-terminal protein kinase; p38, p38-MAPK. 
Effect of MAPK inhibitors on sporamin-induced apoptosis in PANC-1 cells. The combined treatment with sporamin and MAPK inhibitors increased the proportion of apoptotic (annexin V-positive) PANC-1 cells by $21.44 \pm 2.44 \%$ (sporamin with SP600125 versus sporamin or SP600125 treatment alone; $\mathrm{P}<0.01$ ), $19.59 \pm 1.64 \%$ (sporamin with $\mathrm{SB} 203580$ versus sporamin or SB203580 treatment alone; $\mathrm{P}<0.01)$ and $27.58 \pm 3.59 \%$ (sporamin with PD98059 versus sporamin or PD98059 treatment alone; $\mathrm{P}<0.01$ ) (Fig. 4A and B). DAPI nuclear staining. Consistently, PANC-1 cells exposed to sporamin and MAPKs inhibitors exhibited an increase in the number of condensed and fragmented nuclei compared with either single agent alone (Fig. 4C). These results indicated that MAPKs inhibitors enhanced sporamin-induced apoptosis in PANC-1 cells.

\section{Discussion}

The results of the present study demonstrated that sporamin suppressed the growth of PANC-1 cells by inhibition of cellular proliferation and viability (Fig. 3). The suppressive effects of sporamin on cell growth are also partially attributable to the induction of apoptosis (Fig. 4). Furthermore, it was demonstrated that MAPK activation may serve a protective role against the antitumor effects of sporamin, as the combination treatment of MAPK inhibitors and sporamin resulted in increased cell growth suppression and apoptosis.

Sporamin inhibits cell growth and induces apoptosis in colorectal cancer cells (4) and tongue cancer cells (5). The results of the present study demonstrated that sporamin suppressed the growth of PANC-1 cells. Cell growth suppression can be attributable to PC cell apoptosis (10), and it was demonstrated in the present study that sporamin induced apoptosis in PANC-1 cells. The present study also investigated the potential mechanism underlying the antitumor effects of sporamin.

MAPKs are involved in the complex signaling transduction cascades that regulate apoptosis (7). Several previous studies have indicated that tyrosine kinases, the cellular redox state and phosphatases are involved in the activation of stress responses, representing the activation of MAPKs in different cell types subsequent to paclitaxel (11) or tumor necrosis factor (12) treatment. Notably, in the present study, sporamin treatment activated ERK1/2, JNK1/2 and p38 in a concentration-dependent manner (Fig. 1) during the sporamin-induced apoptosis of PANC-1 cells (Fig. 4). This result indicated that MAPK signaling is involved in the regulation of PANC-1 cell apoptosis due to sporamin treatment.

MAPK proteins may serve an important role in the complex regulatory mechanisms that underlie resistance to chemotherapeutics $(13,14)$. In a previous study, the histone deacetylase inhibitor TSA was demonstrated to induce cell growth arrest, apoptosis and activation of ERK1/2. ERK1/2 activation protected gastric carcinoma SGC7901 cells from TSA-induced apoptosis (15). Similarly, the results of the present study demonstrated that MAPK proteins are activated by sporamin treatment, and that MAPK activation could protect PANC-1 cells from sporamin-induced apoptosis. However, ERK1/2 inhibition using PD98059 or U0126 markedly blocked cisplatin-induced apoptosis
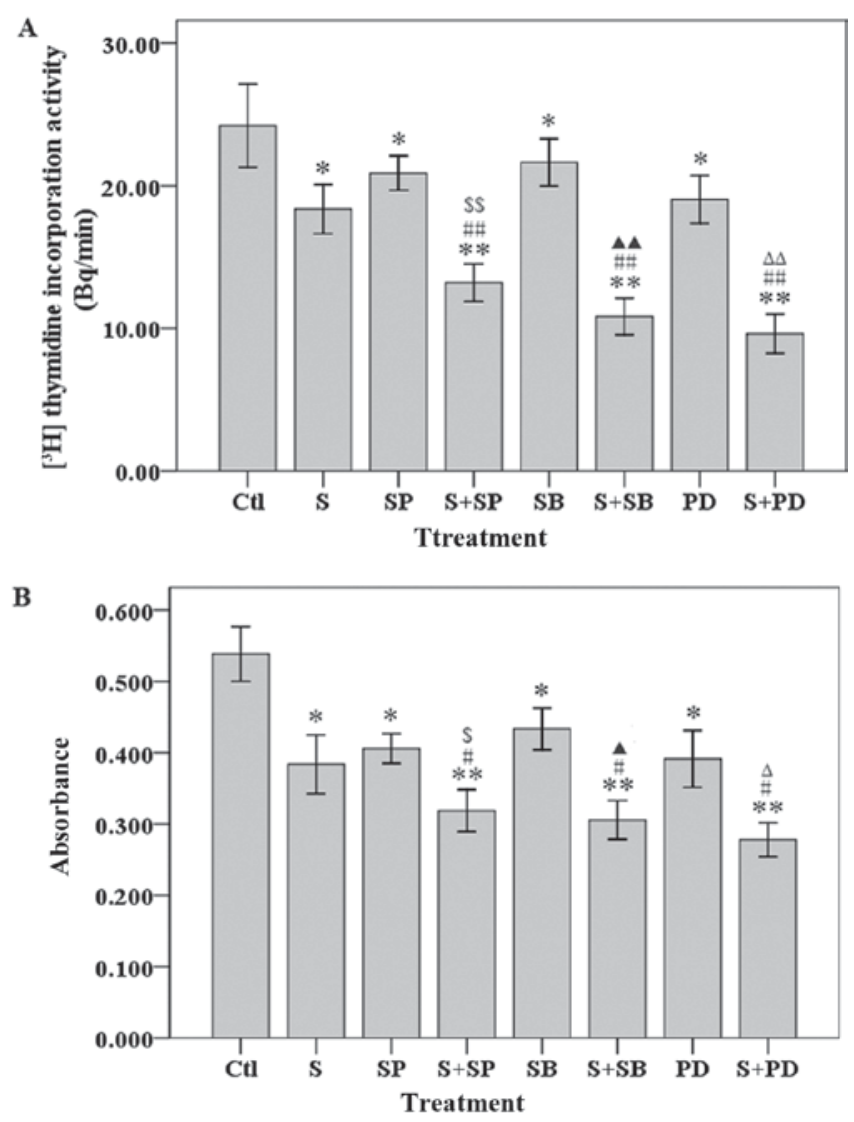

Figure 3. Effects of SP600125, SB203580 and PD98059 on the proliferation and viability of sporamin-treated PANC-1 cells. Cells were pre-incubated with $20 \mu \mathrm{M}$ SP600125, $10 \mu \mathrm{M} \mathrm{SB} 203580$ or $20 \mu \mathrm{M}$ PD98059 for $10 \mathrm{~min}$ prior to $50 \mu \mathrm{M}$ sporamin treatment for $24 \mathrm{~h}$. (A) Cell proliferation and (B) cell viability were determined using ${ }^{3} \mathrm{H}$-thymidine incorporation and MTT assays, respectively. Data are presented as the mean \pm standard deviation; $\mathrm{n}=4$. ${ }^{*} \mathrm{P}<0.05$ and ${ }^{* *} \mathrm{P}<0.01$ vs. untreated control cells; ${ }^{\#} \mathrm{P}<0.05$ and ${ }^{\# \#} \mathrm{P}<0.01$ vs. cells treated with sporamin alone; ${ }^{\$} \mathrm{P}<0.05$ and ${ }^{\$ \$} \mathrm{P}<0.01$ vs. cells treated with SP600125 alone; ${ }^{\mathbf{\Delta}} \mathrm{P}<0.05$ and ${ }^{\boldsymbol{\Delta} \mathbf{\Delta}} \mathrm{P}<0.01$ vs. cells treated with SB203580 alone; ${ }^{\Delta} \mathrm{P}<0.05$ and ${ }^{\Delta \Delta} \mathrm{P}<0.01$ vs. cells treated with PD98059 alone. Ctl, control; S, sporamin; SP, SP600125; SB, SB203580; PD, PD98059.

in human malignant testicular cell lines (16). By contrast, the present study demonstrated that MAPK inhibition by PD98059, SP600125 or SB203580 significantly enhanced the sporamin-induced apoptosis in PANC-1 cells. The differing effects of MAPK inhibitors on apoptosis may be due to the different cancer cell types used by different studies, and their associated genetic/epigenetic statuses. Further studies using other cancer cell lines are therefore required to better characterize this phenomenon.

The MAPK signaling pathways are important in cell growth, drug resistance and malignant transformation in various tumor types (17-19). Understanding the molecular mechanism behind the sporamin-induced MAPK activation should benefit the development of novel therapies for PC. Activation of $\mathrm{p} 38$ is generally associated with the induction of apoptosis, whereas activation of ERK1/2 is associated with cytoprotective effects (17). Therefore, the present study focused on the role of MAPK in sporamin-induced apoptosis. Although inhibition of MAPK enhanced sporamin-induced apoptosis in PANC-1 cells (Fig. 4), the results also indicated that the basal levels of endogenous ERK1/2, JNK1/2 and 

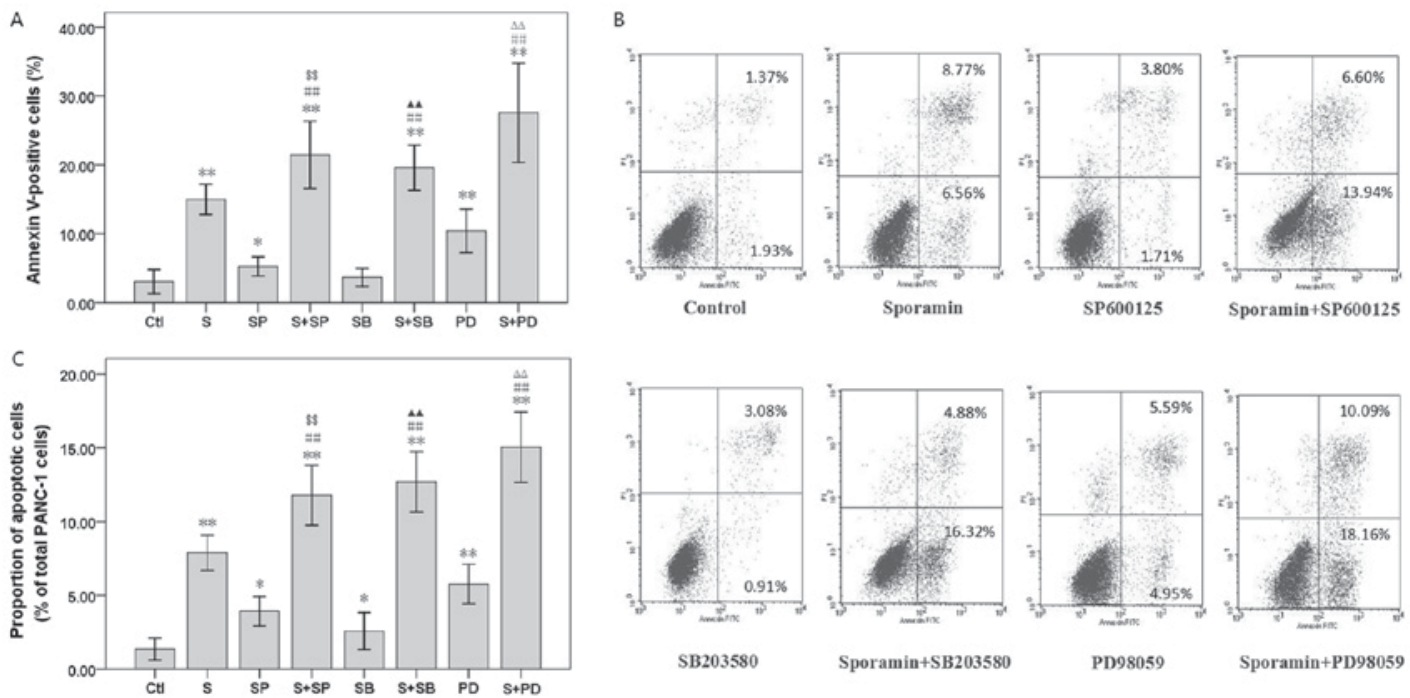

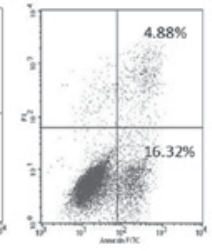

Sporamin+SB203580

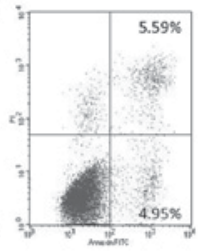

PD98059

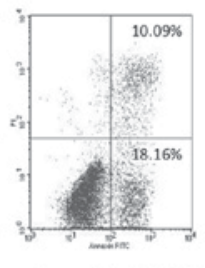

Sporamin+PD98059

Figure 4. Effect of SP600125, SB203580 and PD98059 on the percentage of apoptotic cells in sporamin-treated PANC-1 cells. Cells were pre-incubated with $20 \mu \mathrm{M}$ SP600125, $10 \mu \mathrm{M} \mathrm{SB} 203580$ or $20 \mu \mathrm{M}$ PD98059 for $10 \mathrm{~min}$ prior to treatment with $50 \mu \mathrm{M}$ sporamin for $24 \mathrm{~h}$. (A) The percentage of early apoptotic cells (annexin V-positive, PI-negative) and late apoptotic cells (annexin V- and PI-positive) were assayed by flow cytometry. (B) Representative flow cytometry histograms. (C) Apoptotic morphological changes were used to count apoptotic cells, and subsequently calculate the percentage rate of apoptosis. A total of 6 randomly chosen fields of view were examined with a minimum number of 500 cells scored in each treatment. Data are presented as the mean \pm standard deviation; $n=4 .{ }^{*} \mathrm{P}<0.05$ and ${ }^{* * *} \mathrm{P}<0.01$ vs. untreated control cells; ${ }^{\Delta} \mathrm{P}<0.05$ and ${ }^{\Delta \Delta} \mathrm{P}<0.01$ vs. cells treated with sporamin alone; ${ }^{\$} \mathrm{P}<0.05$ and ${ }^{\$ \$} \mathrm{P}<0.01$ vs. cells treated with SP600125 alone; ${ }^{\mathbf{\Delta}} \mathrm{P}<0.05$ and ${ }^{\mathbf{\Delta}} \mathrm{P}<0.01$ vs. cells treated with $\mathrm{SB} 203580$ alone; ${ }^{\Delta} \mathrm{P}<0.05$ and ${ }^{\Delta \Delta} \mathrm{P}<0.01$ vs. cells treated with PD98059 alone. $\mathrm{PI}$, propidium iodide; Ctl, control; S, sporamin; SP, SP600125; SB, SB203580; PD, PD98059.

p38 phosphorylation serve a role in maintaining the survival of PANC-1 cells. Thus, sporamin may exert a dual role: i) A cytotoxic role by inducing apoptosis; and ii) a protective role by activating MAPK signaling proteins, including ERK1/2, $\mathrm{JNK} 1 / 2$ and $\mathrm{p} 38$.

A previous study has demonstrated that activation of ERK1/2 in gastric cancer cells is associated with increased resistance to chemotherapeutic drugs (20). The activation of ERK1/2, which is associated with proliferative and anti-apoptotic responses, resulted in the generation of resistance to chemotherapeutic drugs in PC cells (21). Increased MAPK activation following chemotherapeutic drug treatments is indicative of a potential increase in the abundance of MAPKs (17-21). In the present study, it was demonstrated that sporamin induced the activation of ERK1/2, JNK1/2 and p38 in a concentration-dependent manner, and that MAPK inhibitors attenuated this effect of sporamin in PANC-1 cells.

MAPK inhibitor treatment not only reduced the constitutive levels of phospho-ERK1/2, phospho-JNK1/2 and phospho-p38, but also inhibited the sporamin-induced activation of MAPK signaling proteins (Fig. 2). MAPK inhibitor treatment also enhanced the inhibition of cell proliferation activity and viability (Fig. 3) and induction of apoptosis (Fig. 4) in sporamin-treated PANC-1 cells. Sporamin and MAPK inhibitor treatments have synergistic effects, indicating at the therapeutic potential of this combination for PC patients.

In summary, the use of MAPK inhibitors to enhance apoptosis via sporamin indicated that MAPK therapies may be advantageous for the efficacy of TI cancer chemotherapy, and that combining TIs with MAPKs inhibitors may be an effective treatment strategy. Therefore, the results of the present study have great potential in the treatment of PC using MAPK inhibitors with TIs.

\section{Acknowledgements}

Not applicable.

\section{Funding}

The present study was supported by grants from the Natural Science Foundation of Zhejiang Province (grant no. LY16H160033), the Public Welfare Technical Applied Research Project of Zhejiang Province (grant no. 2016C33189), the Science and Technology Plans of Taizhou City (grant no. 1701yw07), and the National College Students' Innovation and Entrepreneurship Training Program (grant no. 201710350008).

\section{Availability of data and materials}

The analyzed data sets generated during the study are available from the corresponding author on reasonable request.

\section{Authors' contributions}

JY and CQ conceived and directed the project. CQ and YQ designed the experiments. CQ, YQ, SZ, JZ and XC carried out the experiments. JY and CQ conducted the data analysis and interpreted the results. JY and CQ wrote and edited the paper. All the authors reviewed the manuscript.

\section{Ethics approval and consent to participate}

Not applicable.

\section{Consent for publication}

Not applicable. 


\section{Competing interests}

The authors declare that they have no competing interests.

\section{References}

1. Yeo TP: Demographics, epidemiology, and inheritance of pancreatic ductal adenocarcinoma. Semin Oncol 42: 8-18, 2015.

2. Krška Z, Šváb J, Hoskovec D and Ulrych J: Pancreatic cancer diagnostics and treatment - current state. Prague Med Rep 116: 253-267, 2015

3. Fang EF and $\mathrm{Ng} \mathrm{TB}$ : A trypsin inhibitor from rambutan seeds with antitumor, anti-HIV-1 reverse transcriptase, and nitric oxide-inducing properties. Appl Biochem Biotechnol 175: 3828-3839, 2015.

4. Li PG, Mu TH and Deng L: Anticancer effects of sweet potato protein on human colorectal cancer cells. World J Gastroenterol 19: 3300-3308, 2013.

5. Yao J and Qian C: Sporamin induce apoptosis in human tongue carcinoma cells by down-regulating Akt/GSK-3 signaling. Fundam Clin Pharmacol 25: 229-236, 2011.

6. Kolch W: Meaningful relationships: The regulation of the Ras/Raf/MEK/ERK pathway by protein interactions. Biochem J 351 Pt 2: 289-305, 2000.

7. Peti $\mathrm{W}$ and Page R: Molecular basis of MAP kinase regulation. Protein Sci 22: 1698-1710, 2013.

8. Johnson GL and Lapadat R: Mitogen-activated protein kinase pathways mediated by ERK, JNK, and p38 protein kinases. Science 298: 1911-1912, 2002.

9. Furukawa T: Impacts of activation of the mitogen-activated protein kinase pathway in pancreatic cancer. Front Oncol 5: 23, 2015.

10. Olechowska-Jarząb A, Ptak-Belowska A and Brzozowski T: Terapeutic importance of apoptosis pathways in pancreatic cancer. Folia Med Cracov 56: 61-70, 2016.
11. Gong W, Song Q, Lu X, Gong W, Zhao J, Min P and Yi X: Paclitaxel induced B7-H1 expression in cancer cells via the MAPK pathway. J Chemother 23: 295-299, 2011.

12. Xu X, Tu L, Jiang W, Feng W, Zhao CX and Wang DW: Bradykinin prevents the apoptosis of NIT-1 cells induced by TNF- $\alpha$ via the PI3K/Akt and MAPK signaling pathways. Int J Mol Med 29: 891-898, 2012.

13. Grossi V, Peserico A, Tezil T and Simone C: P38 $\alpha$ MAPK pathway: A key factor in colorectal cancer therapy and chemoresistance. World J Gastroenterol 20: 9744-9758, 2014.

14. Tan W, Yu HG and Luo HS: Inhibition of the p38 MAPK pathway sensitizes human gastric cells to doxorubicin treatment in vitro and in vivo. Mol Med Rep 10: 3275-3281, 2014

15. Yao J, Qian CJ, Ye B, Zhang X and Liang Y: ERK inhibition enhances TSA-induced gastric cancer cell apoptosis via $\mathrm{NF}-\kappa \mathrm{B}-d e p e n d e n t$ and Notch-independent mechanism. Life Sci 91: 186-193, 2012.

16. Schweyer S, Soruri A, Meschter O, Heintze A, Zschunke F, Miosge N, Thelen P, Schlott T, Radzun HJ and Fayyazi A: Cisplatin-induced apoptosis in human malignant testicular germ cell lines depends on MEK/ERK activation. Br J Cancer 91: 589-598, 2004.

17. Xia Z, Dickens M, Raingeaud J, Davis RJ and Greenberg ME: Opposing effects of ERK and JNK-p38 MAP kinases on apoptosis. Science 270: 1326-1331, 1995.

18. Huang P, Han J and Hui L: MAPK signaling in inflammation-associated cancer development. Protein Cell 1: 218-226, 2010.

19. Haagenson KK and Wu GS: The role of MAP kinases and MAP kinase phosphatase-1 in resistance to breast cancer treatment. Cancer Metastasis Rev 29: 143-149, 2010.

20. Liu L, Zhang H, Sun L, Gao Y, Jin H, Liang S, Wang Y, Dong M, Shi Y, Li Z and Fan D: ERK/MAPK activation involves hypoxia-induced MGr1-Ag/37LRP expression and contributes to apoptosis resistance in gastric cancer. Int J Cancer 127: 820-829, 2010.

21. Zheng C, Jiao X, Jiang Y and Sun S: ERK1/2 activity contributes to gemcitabine resistance in pancreatic cancer cells. J Int Med Res 41: 300-306, 2013. 